\title{
CORRIGENDUM
}

\section{Generation of cancer stem-like cells through the formation of polyploid giant cancer cells}

S Zhang, I Mercado-Uribe, Z Xing, B Sun, J Kuang and J Liu

\author{
Oncogene (2014) 33, 134; doi:10.1038/onc.2013.318
}

Correction to: Oncogene (2014) 33, 116-128; doi:10.1038/ onc.2013.96; published online 25 March 2013

The authors of this study have noticed an error in Figures $3 C$ and $4 C$ of their paper. In Figure 3C, the same image from MDA-MB-231 (Oct3/4) was erroneously used for Hey (Oct3/4). The correct image for Hey (Oct3/4) is now provided. In Figure $4 \mathrm{C}$ an image with faint yellow was erroneously used for RFP, the correct image for RFP together with matched eGFP and merged image is now provided. The errors were unintentionally introduced during figure preparation and do not in any way alter the results or conclusions of this study. The authors apologize that these errors were not detected earlier. The corrected Figures $3 \mathrm{C}$ and $4 \mathrm{C}$ are shown below.

The rare fused SKOv3 cells showed clonal growth with mixed regular sized and large cancer cells.
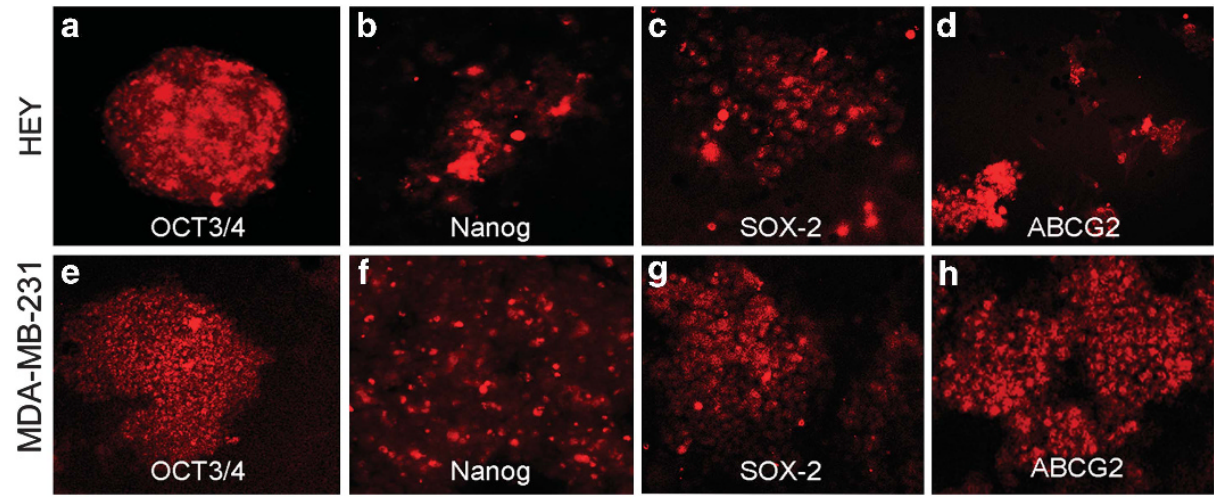

Figure 3.
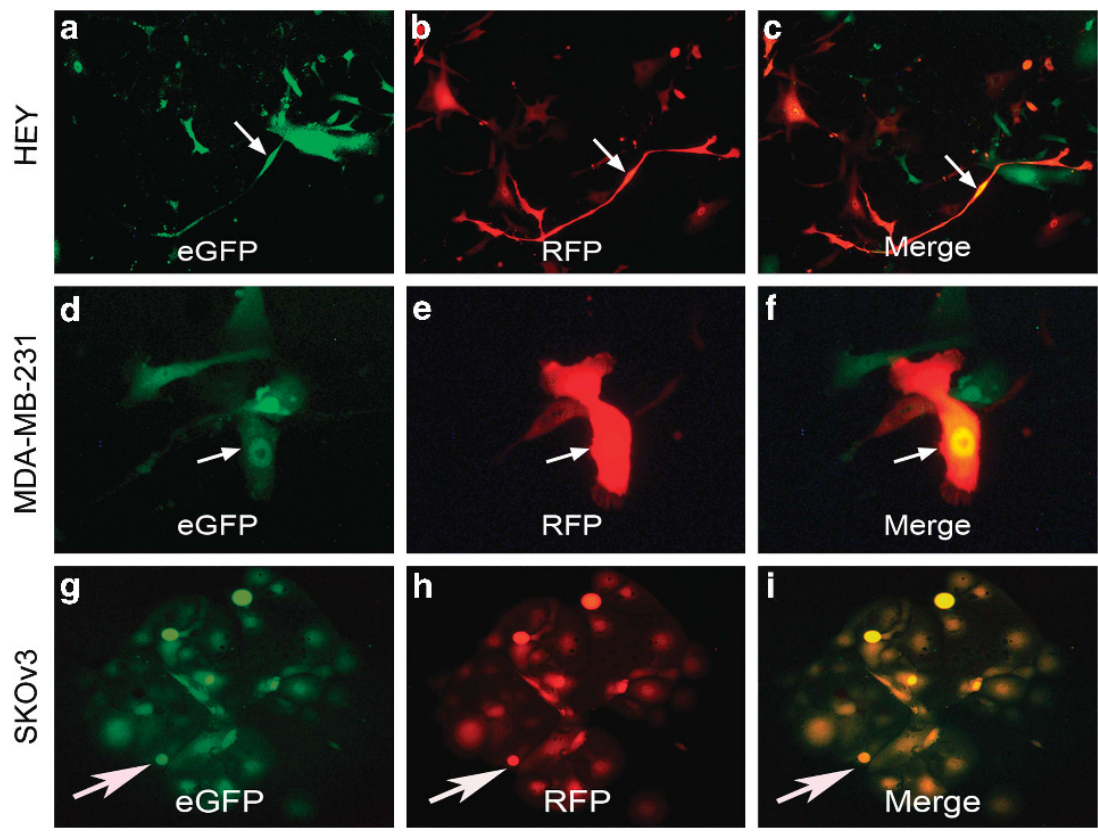

Figure 4. 